\section{AUTHOR DISCLOSURE} INFORMATION

The present report did not receive any support from pharmaceutical companies.

Dr Gobbi has been a speaker for Eli Lilly Canada and Merck Canada and has received grant/honoraria from GlaxoSmithKline, Merck \& Co., AstraZeneca.

\author{
Gabriella Gobbi, MD, PhD \\ Neurobiological Psychiatry Unit \\ Department of Psychiatry \\ McGill University \\ Montreal, Quebec, Canada \\ gabriella.gobbi@mcgill.ca
}

\section{REFERENCES}

1. Kendell R, Chalmers J, Platz C. Epidemiology of puerperal psychoses. Br J Psychiatry. 1987;150:662-673.

2. Sit D, Rothschild AJ, Wisner KL. A review of postpartum psychosis. $J$ Womens Health. 2006;15:352-368.

3. Appleby L, Mortensen PB, Faragher EB. Suicide and other causes of mortality after post-partum psychiatric admission Br J Psychiatry. 1998;173:209-211.

4. Spinelli MG. Maternal infanticide associated with mental illness: prevention and promise of saved lives. Am J Psychiatry. 2004;161:1548-1557.

5. Brockington IF, Hillier VF, Francis AF, et al. Definitions of mania: concordance and prediction of outcome. Am J Psychiatry. 1983;140:435-439.

6. Dean C, Kendell RE. The symptomatology of puerperal illnesses. Br J Psychiatry. 1981;139:128-133.

7. Wisner KL, Peindl K, Hanusa BH. Symptomatology of affective and psychotic illnesses related to childbearing. J Affect Disord. 1994;30:77-87.

8. Protheroe C. Puerperal psychoses: a long-term study 1927-1961. Br J Psychiatry. 1969;115:9-30.

9. Doucet $\mathrm{S}$, Jones I, Letourneau N, et al. Interventions for the prevention and treatment of postpartum psychosis: a systematic review. Arch Womens Ment Health. 2011;14:89-98.

10. Sharma V. Treatment of postpartum psychosis: challenges and opportunities. Curr Drug Saf. 2008;3:76-81.

11. Kornhuber J, Weller M. Postpartum psychosis and mastitis: a new indication for clozapine? Am J Psychiatry. 1991;148: 1751-1752.

12. Sharma V, Smith A, Mazmanian D. Olanzapine in the prevention of postpartum psychosis and mood episodes in bipolar disorder. Bipolar Disord. 2006;8:400-404.

13. Targum S, Davenport Y, Webster M. Postpartum mania in bipolar manic-depressive patients withdrawn from lithium carbonate. J Nerv Ment Dis. 1979; 167:572-574.

14. Ahokas A, Aito M, Rimon R. Positive treatment effect of estradiol in postpartum psychosis: a pilot study. J Clin Psychiatry. 2000;61:166-169.

15. Austin MP. Puerperal affective psychosis: is there a case for lithium prophylaxis? Br J Psychiatry. 1992;161:692-694.

16. Cohen LS, Sichel DA, Robertson LM, et al. Postpartum prophylaxis for women with bipolar disorder. Am J Psychiatry. 1995;152:1641-1645

17. Kumar C, McIvor RJ, Davies T, et al. Estrogen administration does not reduce the rate of recurrence of affective psychosis after childbirth. J Clin Psychiatry. 2003;64:112-118.

18. Wisner KL, Hanusa BH, Piendl KS, et al. Prevention of postpartum episodes in women with bipolar disorder. Biol Psychiatry. 2004;56:592-596.

19. Comai S, Tau M, Pavlovic Z, et al. The psychopharmacology of aggressive behavior: a translational approach: part 2: clinical studies using atypical antipsychotics, anticonvulsants, and lithium. J Clin Psychopharmacol. 2012;32:237-260.

20. Sharma V, Mazmanian D. Sleep loss and postpartum psychosis. Bipolar Disord. 2003;5:98-105.

\title{
OPEN
}

\section{Impact of Lithium Treatment on FGF-23 Serum Concentrations in Depressive Patients}

To the sociated with the risk to develop severe medical disorders. ${ }^{1}$ Indeed, depression increases the risk of cardiovascular disease by 1.5-fold to 2-fold, of stroke by 1.8-fold, of Alzheimer disease by 2.1-fold, of diabetes by $60 \%$, and of cancer by 1.3 -fold to 1.8 fold. ${ }^{1}$ Fibroblast growth factors (FGFs) are best known for their regulatory roles in cell growth, differentiation, and morphogenesis in early stages of neural development and have been discussed as switch genes, biomarkers, and treatment targets for affective disorders recently. ${ }^{2,3}$ However, at least FGF23 has also been proposed as a cardiovascular risk marker, ${ }^{4}$ a central player of disordered mineral metabolism, ${ }^{5}$ and acts to decrease phosphate, 1,25-dihydroxyvitamin $\mathrm{D}$, and parathyroid hormone levels. ${ }^{5}$

A close, bidirectional relationship exists between depression and cardiovascular disease. ${ }^{1}$ Indeed, major depression is associated with an increased risk of coronary artery disease, myocardial infarction, congestive heart failure, and isolated systolic hypertension leading to increased mortality and morbidity in patients. ${ }^{1}$ Moreover, a strong relationship has been described between severe coronary and aortic calcifications, intima thickness, osteoporosis, and depressive disorders. ${ }^{1}$

Fibroblast growth factor 23 lowers serum levels of $1,25(\mathrm{OH})_{2} \mathrm{D}_{3}$, which in turn up-regulates renal and intestinal phosphate and calcium transport. ${ }^{6-9}$ In mice, it was shown recently that lithium treatment up-regulates FGF-23 formation, an effect paralleled by substantial decrease of serum $1,25(\mathrm{OH})_{2} \mathrm{D}_{3}$ and phosphate concentrations. ${ }^{10}$ The present study explores the effect of lithium treatment on serum FGF-23, $1,25(\mathrm{OH})_{2} \mathrm{D}_{3}$, calcium, and phosphate concentrations in depressed patients.

A total of 95 acute depressive patients (age $48 \pm 14$ years) were recruited for this study. Inclusion criteria consist of unipolar depression, age older than 18 years, indication for antidepressant pharmacotherapy, insufficient response to an adequate antidepressant pretreatment and clinical indication for lithium augmentation, hamilton depression rating score greater than 12 , and written informed consent. Diagnosis was confirmed on the basis of the Structured Clinical Interview for Diagnostic and Statistical Manual of Mental Disorders. Fibroblast growth factor 23 serum concentrations were measured first in medicated patients before lithium augmentation and then after 4 weeks of medication with lithium. Detailed clinical data of the patients have already been published. ${ }^{11}$ All patients reached a lithium serum level of more than $0.4 \mathrm{mmol} / \mathrm{L}$. Serum FGF-23 concentrations were measured by enzyme-linked immunosorbent assay (Immutopics International, California; AVP EIA kit, Phoenix Europe, Karlsruhe, Germany). enzyme-linked immunosorbent assay kits were employed to determine serum concentrations of $1,25(\mathrm{OH})_{2} \mathrm{D}_{3}$ (IDS, Boldon, United Kingdom). Data are provided as mean \pm SEM; $n$ represents the number of independent experiments. All data were tested for significance using unpaired Student $t$ test. Only results with $P<0.05$ were considered statistically significant. As illustrated in Figure 1, lithium treatment was followed by a marked increase of serum FGF-23 concentration. As shown in Figure 1, lithium treatment significantly decreased serum $1,25(\mathrm{OH})_{2} \mathrm{D}_{3}$ 

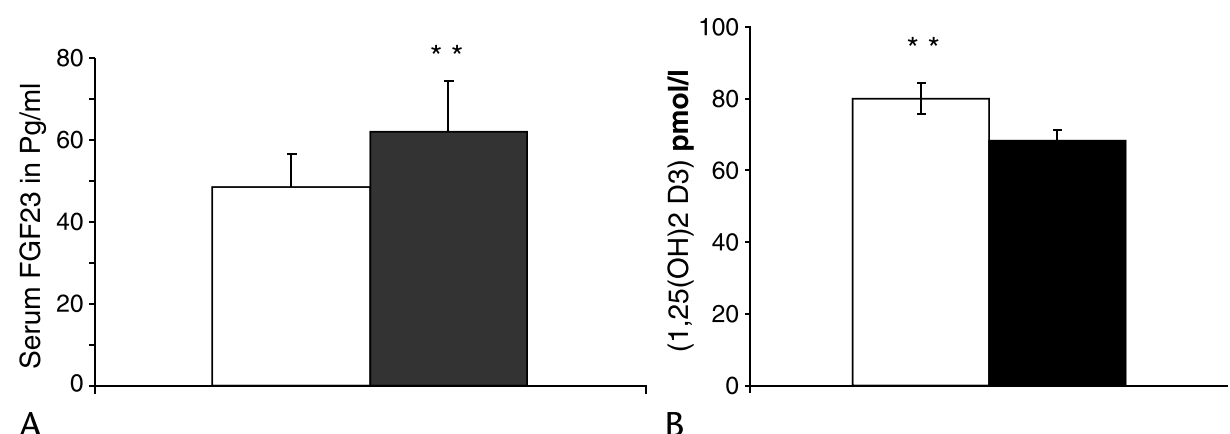

A

\section{B}

FIGURE 1. Serum FGF-23 and $1,25(\mathrm{OH})_{2} \mathrm{D}_{3}$ levels/concentrations before and after lithium treatment. Arithmetic means \pm SEM $(\mathrm{n}=95)$ of serum FGF-23 (A) and $1,25(\mathrm{OH})_{2} \mathrm{D}_{3}$ levels $(\mathrm{B})$ before (white bars) and after (black bars) lithium treatment. ${ }^{* *} P<0.01$ indicates significant difference from respective value before treatment.

concentration. Lithium treatment significantly decreased serum phosphate concentrations (data not shown).

\section{DISCUSSION}

The present observations reveal that lithium treatment results in a significant increase of serum FGF-23 concentration, a significant decrease of serum $1,25(\mathrm{OH})_{2} \mathrm{D}_{3}$ concentration, and a significant decrease of serum phosphate concentration.

Neuroprotective and procognitive effects of lithium have been evidenced in both experimental research and in clinical studies using brain imaging, suggesting lithium to be effective in the prophylaxis of dementia and in neurodegenerative disorders, such as Huntington disease, Parkinson disease, and amyotrophic lateral sclerosis. ${ }^{12}$ However, the exact mechanism of lithium's neuroprotective effect is largely unknown. Interestingly, lithium augmentation leads to a brain-derived neurotrophic factor increase, ${ }^{11}$ and lithium acts as a GSK3 $\beta$ inhibitor. ${ }^{13}$ Fibroblast growth factor 2, IGF-1, and brain-derived neurotrophic factor can stimulate the magnitude of Akt activation. ${ }^{13}$ At least FGF-2 has been shown to promote the survival of hippocampal neurons significantly more effectively than the 2 other peptides. ${ }^{13}$ In line with our data, the neuroprotective effect of lithium might be at least partly mediated by an increase of FGF-23.

Enhanced serum phosphate concentration predisposes to vascular calcification ${ }^{4-9}$ and is considered a predictor of early mortality. ${ }^{4-9}$ Along those lines, FGF-23 deficiency is followed by increase of serum phosphate, calcium, and $1,25(\mathrm{OH})_{2} \mathrm{D}_{3}$ concentrations with subsequent vascular calcification, decrease of bone density, and reduction of life-span. ${ }^{4-9}$ Conversely, lowdose lithium uptake in tap water has been shown to promote longevity in humans. ${ }^{14}$ In conclusion, our observations might partly explain these findings as lithium might decrease phosphate concentrations, decrease vascular calcification, and thereby increase the life-span.

At least in theory, the effect of lithium on FGF-23 serum levels may in part be due to polyuria and dehydration. ${ }^{15}$ Serum FGF23 levels are enhanced in gene-targeted mice lacking kinases involved in stimulation of renal tubular $\mathrm{NaCl}$ transport, and thus required for adequate renal salt and fluid reabsorption as well as hydration. ${ }^{15,16}$

The increase of FGF-23 serum concentration presumably accounts for the decrease of serum $1,25(\mathrm{OH})_{2} \mathrm{D}_{3}$ concentrations after lithium treatment, as FGF-23 down-regulates the renal $1 \alpha$ hydroxylase and thus the formation of $1,25(\mathrm{OH})_{2} \mathrm{D}_{3}$. ${ }^{6,8}$ $1,25(\mathrm{OH})_{2} \mathrm{D}_{3}$ stimulates both renal and intestinal phosphate transport. ${ }^{17}$ Beyond its effect on $1,25(\mathrm{OH})_{2} \mathrm{D}_{3}$ formation, FGF23 inhibits renal tubular phosphate reabsorption more directly. ${ }^{6,8}$ The effect of FGF-23 on $1,25(\mathrm{OH})_{2} \mathrm{D}_{3}$ formation and renal tubular phosphate transport presumably accounts for the observed decrease of serum phosphate concentration. High serum phosphate concentrations foster vascular calcification and eventually lead to early appearance of age-related disorders and decrease of life-span. ${ }^{18,19}$ Fibroblast growth factor 23 is a powerful inhibitor of aging. ${ }^{19}$ Lack of FGF-23 leads to premature appearance of a wide variety of age-related disorders, such as osteopenia, osteoporosis, impaired angiogenesis, enhanced erythrocyte turnover, pulmonary emphysema, skin atrophy, infertility, hearing loss, neuron degeneration, Parkinson disease, cognitive impairment, neoplasms, and inflammation. ${ }^{19}$ In view of the present observations, lithium may counteract at least some of those disorders observed in FGF-23 deficiency. However, the observation of an increased bone mass after treatment with lithium might underlie our observed effect of lithium on FGF-23 concentrations. ${ }^{20}$ However, our data are preliminary; as in this study, no placebo-treated group was observed, and the effects on FGF-23 and $1,25(\mathrm{OH})_{2} \mathrm{D}_{3}$ were rather small in magnitude. However, small effects might cause changes when medications are used chronically.

In conclusion, lithium treatment might lead to an up-regulation of FGF-23 serum concentration, which in turn might result in decreased serum $1,25(\mathrm{OH})_{2} \mathrm{D}_{3}$ and phosphate concentrations. Antidepressant mechanisms that may underlie the observed effect of lithium on FGF-23 are the proper formation of synaptic connections in the cerebral cortex, the maturation and survival of catecholamine neurons, and neurogenesis. ${ }^{2}$

Our data are in line with an observed dysregulation of several FGF system transcripts in the frontal cortical regions of the brains of human subjects with major depressive disorder. ${ }^{21}$ Fibroblast growth factor is a growth factor essential for the proper formation of synaptic connections in the cerebral cortex, maturation and survival of catecholamine neurons, and neurogenesis. $^{21,22}$ Moreover, a correlation between antidepressant treatments and FGF expression in the cerebral cortex and hippocampus has been observed. 22,23

Our data are in line with previous observations showing that the FGF system might be altered in post-mortem brains of individuals with major depressive disor$\mathrm{der}^{22}$ and can be modulated by antidepressant treatment. ${ }^{22,23}$ Moreover, a change of the FGF system after acute social defeat has been observed, and FGF showed an antidepressant effect in rat. $^{23}$

In this context, the stimulation of FGF via lithium might be linked to its known GSK $3 \beta$ inhibitory action. ${ }^{1,10}$ In summary, the effects of lithium on FGF-23 serum levels may protect from vascular calcification and the appearance of age-related disorders. 


\section{ACKNOWLEDGMENT}

H. Fakhri, R. Ricken, and M. Adli share the first authorship.

Supported by the Deutsche Forschungsgemeinschaft (LA 2694/1-2).

\section{AUTHOR DISCLOSURE INFORMATION} interest.

The authors declare no conflicts of

*Berlin Research Network of Depression: Christoph Richter, MD; Bruno Steinacher, MD, PhD; Tom Bschor, MD, PhD; Sebastian Erbe, MD; Albert Dieffenbacher, MD, PhD; Samuel Elstner, MD; Marcus Gastpar, MD, PhD; Brigitte SchulzRatei, MD, PhD; Hubertus Himmerich, MD, PhD; Joachim Zeiler, MD, PhD; Alexandra Lingesleben, MD; Andreas Heinz, MD, PhD; Jürgen Gallinat, MD, PhD; Meryam Schouler-Ocak, MD, PhD; Gernot Deter, MD; Hartmut Dormhagen, MD; Rainer Hellweg, MD, PhD; Phillip Sterzer, MD, PhD; Andreas Ströhle, MD, PhD; Thomas Stamm, MD; Mazda Adli, MD, PhD; Roland Ricken, MD; Friedel M. Reischies, MD, PhD; Peter Bräunig, MD, PhD; Ramona Pietsch, MD; Iris Hauth, MD; Frank Godemann, MD, PhD; Peter $\mathrm{Neu}, \mathrm{MD}, \mathrm{PhD}$.

This is an open access article distributed under the terms of the Creative Commons Attribution-NonCommercialNoDerivatives 3.0 License, where it is permissible to download and share the work provided it is properly cited. The work cannot be changed in any way or used commercially.

Hajar Fakhri, MD

Department of Physiology University of Tübingen Tübingen, Germany

Roland Ricken, MD

Mazda Adli, MD, PhD Department of Psychiatry and Psychotherapy Charité University Medicine Berlin Campus Mitte Berlin, Germany

Abul Fajol, MD Department of Physiology University of Tübingen Tübingen, Germany

Marc Walter, MD, PhD University Psychiatric Clinics University of Basel Basel, Switzerland

Michael Föller, MD, PhD

Berlin Research Network of Depression*

Florian Lang, MD, PhD

Department of Physiology University of Tübingen Tübingen, Germany
Undine E. Lang, MD, PhD

University Psychiatric Clinics University of Basel Basel, Switzerland Undine.Lang@upkbs.ch

Claudia Lange, MSc University Psychiatric Clinics University of Basel Basel, Switzerland

\section{REFERENCES}

1. Lang UE, Borgwardt S. Molecular mechanisms of depression: perspectives on new treatment strategies. Cell Physiol Biochem. 2013;31:761-777.

2. Zhang X, Bao L, Yang L, et al. Roles of intracellular fibroblast growth factors in neural development and functions. Sci China Life Sci. 2012;55:1038-1044.

3. Turner CA, Watson SJ, Akil H. The fibroblast growth factor family: neuromodulation of affective behavior Neuron. 2012;76:160-174.

4. Heine GH, Seiler S, Fliser D. FGF-23: the rise of a novel cardiovascular risk marker in CKD. Nephrol Dial Transplant. 2012;27:3072-3081.

5. Komaba H, Fukagawa M. The role of FGF23 in CKD - with or without Klotho. Nat Rev Nephrol. 2012;8:484-490.

6. Gattineni J, Twombley K, Goetz R, et al Regulation of serum $1,25(\mathrm{OH})_{2}$ Vitamin D3 levels by fibroblast growth factor 23 is mediated by FGF receptors 3 and 4 . Am J Physiol Renal Physiol. 2011:301:F371-F377.

7. Inoue Y, Segawa H, Kaneko I, et al. Role of the vitamin D receptor in FGF23 action on phosphate metabolism. Biochem J. 2005;390:325-331.

8. Shimada T, Mizutani S, Muto T, et al. Cloning and characterization of FGF23 as a causative factor of tumor-induced osteomalacia. Proc Natl Acad Sci US A. 2001;98:6500-6505.

9. Marsell R, Jonsson KB. The phosphate regulating hormone fibroblast growth factor- 23 . Acta Physiol (Oxf). 2010;200:97-106.

10. Fakhri H, Pathare G, Fajol A, et al. Regulation of mineral metabolism by lithium. Pflugers Arch. 2014;466:467-475.

11. Ricken R, Adli M, Lange C, et al. Brain-Derived Neurotrophic Factor serum concentrations in acute depressive patients increase during lithium augmentation of antidepressants. J Clin Psychopharmacol. 2013;33:806-809.

12. Forlenza OV, de Paula VJ, Machado-Vieira R, et al. Does lithium prevent Alzheimer's disease? Drugs Aging. 2012;29:335-342.

13. Johnson-Farley NN, Patel K, Kim D, et al Interaction of FGF-2 with IGF-1 and BDNF in stimulating Akt, ERK, and neuronal survival in hippocampal cultures. Brain Res. 2007;1154:40-49.

14. Zarse K, Terao T, Tian J, et al. Low-dose lithium uptake promotes longevity in humans and metazoans. Eur J Nutr. 2011;50:387-389.

15. Sugawara M, Hashimoto $K$, Ota $Z$. Involvement of prostaglandin E2, cAMP, and vasopressin in lithium-induced polyuria. Am J Physiol. 1988;254:R863-R869.

16. Pathare G, Föller M, Michael D, et al. Enhanced FGF23 serum concentrations and phosphaturia in gene-targeted mice expressing WNK-resistant Spak. Kidney Blood Press Res. 2012;36:355-364

17. Brown AJ, Finch J, Slatopolsky E. Differential effects of 19-nor-1,25-dihydroxyvitamin D2 and 1,25-dihydroxyvitamin D3 on intestinal calcium and phosphate transport. J Lab Clin Med. 2002;139:279-284.

18. Rodriguez M, Martinez-Moreno JM, Rodríguez-Otiz ME, et al. Vitamin D and Vascular Calcification in Chronic Kidney Disease. Kidney Blood Press Res. 2011;34:261-268.

19. Kuro-o M. Klotho, phosphate and FGF-23 in ageing and disturbed mineral metabolism. Nat Rev Nephrol. 2013;9:650-660.

20. Zamani A, Omrani GR, Nasab MM Lithium's effect on bone mineral density. Bone. 2009;44(2):331-334.

21. Evans SJ, Choudary PV, Neal CR, et al. Dysregulation of the fibroblast growth factor system in major depression. Proc Natl Acad Sci U S A. 2004;101:15506-15511.

22. Bachis A, Mallei A, Cruz MI, et al. Chronic antidepressant treatments increase basic fibroblast growth factor and fibroblast growth factor-binding protein in neurons. Neuropharmacol. 2008;55:1114-1120.

23. Maragnoli ME, Fumagalli F, Gennarelli M et al. Fluoxetine and olanzapine have synergistic effects in the modulation of fibroblast growth factor 2 expression within the rat brain. Biol Psychiatry. 2004:55:1095-1102

\section{Lamotrigine Reduces Affective Instability in Depressed Patients With Mixed Mood and Anxiety Disorders}

\section{To the Editors:}

There is a puzzling ambiguity about the efficacy of lamotrigine as a treatment of recurrent bipolar depression. ${ }^{1-3} \mathrm{~A}$ summary of 5 short-term studies (mostly for depression in bipolar disorders) concluded that the results were statistically negative with a few exceptions on secondary measures. ${ }^{4}$ A subsequent meta-analysis 